\title{
As concepções de linguagem e a formação de professores do ensino bilingue em Moçambique
}

\author{
Dagoberto Buim Arena ${ }^{1}$ \\ Lourenço Alfredo Covane ${ }^{2}$
}

\section{RESUMO}

Este artigo propõe a reformulação dos planos curriculares de formação de professores primários em Moçambique, no que diz respeito às concepções da linguagem. Para os estudiosos do marxismo e filosofia da linguagem os quais apoiam este trabalho, a natureza da linguagem é social, por esse motivo deve ser estudada no meio das relações sociais onde ela acontece. A pesquisa privilegia a leitura de trabalhos académicos produzidos, principalmente no contexto nacional, passando pela análise dos planos curriculares de formação de professores primários e da legislação sobre o Sistema Nacional da Educação (SNE). As conclusões apontam que foram construídos, desde a Independência Nacional até a data de hoje, vários modelos de formação de professores primários e, em quase todos, domina uma abordagem fônica no ato de apropriação da linguagem, tanto na disciplina de português quanto na disciplina da língua materna.

PALAVRAS-CHAVE: Moçambique. Formação de professores. Ensino bilingue. Interacção verbal.

The conceptions of language and the formation of teachers of bilingual teaching in Mozambique

\footnotetext{
ABSTRACT

This article proposes the reformulation of curricular plans for primary teacher education in Mozambique, regarding the conceptions of language. For the scholars of Marxism and philosophy of language on which this

${ }^{1}$ Professor Associado do Departamento de Didática e do Programa de Pós-Graduação em Educação da UNESP, Campus de Marília-SP. https://orcid.org/0000-0001-9285-6487.dagobertobuim@gmail.com

${ }^{2}$ Docente da Universidade Pedagógica, Moçambique. https://orcid.org/0000-0002-3253-4918. lcovane@hotmail.com
} 
work rests, the nature of language is social, so it must be studied in the social relations where it happens. The research privileges the reading of academic works produced, mainly in the national context, going through the analysis of curricular plans of primary teachers formation and the legislation about the National Education System (SNE). The conclusions point out that, since National Independence to date, several models of primary teacher education have been built, and in almost all of them, a phonic approach to the act of language appropriation in Portuguese and in the mother tongue discipline is mastered.

KEYWORDS: Mozambique. Teacher formation. Bilingual Education. Verbal interaction

\section{Introdução}

A formação de professores de línguas é uma área de maior interesse na sociedade como a moçambicana, dominada pela interconexão de linguagens. Esta afirmação pode ser constatada nos diferentes ambientes sociais por estudiosos do mundo inteiro. Este estudo faz uma reflexão acerca das concepções da linguagem que permeiam a formação de professores do ensino bilíngüe em Moçambique e, a partir dessa compreensão, propor uma reformulação dos planos curriculares de português e da língua materna.

Essa prática histórica, a formação de professores, construída ao longo do tempo, vem sofrendo interferências significativas do próprio ambiente educativo, questionando o papel do professor na vida real dos cidadãos. Este trabalho traz contribuições ao propor essa discussão para que seja repensada a formação de professores de forma condizente com uma sociedade mais conectada e mais plural.

Dividimos o texto de forma a que possamos apresentar um pouco da história da formação de professores em Moçambique, destacando os modelos de formação de professores construídos após a Indenpendência Nacional, em 
1975, e a visão do ensino de línguas, seguidos de uma tentativa de ressignificar o conceito de formação de professores, ampliando-o na dimensão social. Esta reflexão permite compreender os motivos que justificam a mudança constante dos modelos de formação de professores no que diz respeito ao ensino de línguas. Após esta reflexão, apresentamos as principais contribuições dos estudos bakhtinianos para a formação de professores da área da linguagem.

\section{Um pouco da história da formação de professores primários e discussões sobre o ensino de línguas.}

Todos os sistemas educativos têm uma longa história de formação de professores, durante a qual são construídos modelos curriculares que podem prevalecer ou serem alterados de acordo com a visão da sociedade sobre a educação. A história da educação em Moçambique divide-se em dois momentos principais: Era colonial e Pós-colonial. Na era colonial, o ensino praticado pelo colonizador português compreende entre 1930 e 1974 e fundase numa filosofia elitista. Por um lado, as escolas oficiais educavam o filho do branco para desempenhar funções sociais e políticas importantes e, por outro, as escolas indígenas educavam o negro como mão de obra.

O período pós-colonial parte de 1975 até a data de hoje, a educação é vista como um direito de todos os cidadãos, independentemente da religião, cultura e língua. Destacamos três fases neste período. A primeira fase vai de 1974 até 1977 e coincide com a "afirmação do poder da Frelimo" (MAZULA, 1995, p. 148), (Frente de Libertação de Moçambique). Para este autor, a afirmação do poder significa "extensão da hegemonia política da Frelimo a todo o território, a alteração profunda das relações sociais, que implicava em mudança de mentalidade e de comportamento" com reflexo "na abertura de escolas, postos de saúde, na retomada de terras férteis, outrora apropriadas por colonos." (MAZULA, 1995, p. 148). Esse período apresenta-se, historicamente, como um marco importantíssimo, porque delimita o fim da 
colonização, com a assinatura dos Acordos de Lusaka, a 7 de Setembro de 1974 entre a Frelimo e o Governo Português e os primeiros anos da independência do país. Havia, no seio da Frelimo e das populações, uma compreensão generalizada de que o analfabetismo constituía o maior obstáculo ao desenvolvimento econômico, pelo que devia ser combatido o mais rapidamente possível.

Esse momento, marcado pela explosão escolar foi muito importante, mas ao mesmo tempo, impôs muitos desafios ao sistema educaional. Por exemplo, a relação professor-aluno cresceu substancialmente. Ao menos até 1980, havia "professores que ensinavam a centenas de alunos de várias classes e idades" (MAZULA, 1995, p. 165). Esse fenómeno levou o Ministério da Educação e Cultura a implementar reformas, como por exemplo a formação acelerada de professores e a contratação de pessoas sem formação psicopedagógica "para o Ciclo Preparatório $\left(1^{\circ}\right.$ e $2^{\circ}$ anos $)$ do $1^{\circ}$ nível do ensino Liceal." (MINEDH, 2017, p. 45).

É importante destacar que a esses desafios colocados nesse período, também se somavam discussões sobre as línguas de ensino, sobretudo na alfabetização e nas primeiras classes do ensino primário para atender à diversidade que se colocava, constituindo-se temas polêmicos sobre os quais não houve, na altura, desfecho. Segundo Mazula (1995, p. 165),

concluiu-se que tinha, apenas, iniciado um debate sobre um tema em si complexo, que ele devia ser continuado mais profundamente com trabalho de pesquisa e estudos mais especializados, envolvendo instituições científicas existentes no país, como o INDE e a Universidade, fazendo intercambio com instituições de outros país, particularmente africanos, envolvendo, também, as estrtuturas do Partido e Deputados das Assembleias Locais.

Nesses debates, é importante destacar o papel da Universidade Eduardo Mondlane (UEM), através do Departamento de Letras Modernas 
da Faculdade de Letras, no estudo científico das línguas moçambicanas. Sobre o assunto Ngunga e Faquir (2012, p. 3), assim, se expressam:

O estudo científico das línguas moçambicanas começa nos finais da década de setenta, na Faculdade de Letras da Universidade Eduardo Mondlane com a introdução de algumas disciplinas de linguística bantu nos cursos ali oferecidos e nos de Formação de Professores da Faculdade Preparatória.

Não tendo se concluído ainda o debate sobre as línguas moçambicanas, prevaleceu a língua portuguesa como o único meio de alfabetização e de formação de professores, como reflexo da política colonial. Assim, a língua portuguesa era vista como única língua "mais desenvolvida e melhor equipada capaz de cumprir as exigências de comunicação num estado moderno que na altura da independência se ansiava construir" (NGUNGA; BAVO, 2011, p. 1). Desta forma, podemos entender a razão por que a questão das línguas maternas moçambicanas foi sempre jogada em segundo plano.

Os primeiros Centros de Formação de Professores Primários (CFPPs) em Moçambque criados nesse período são os modelos de $6^{\text {a }}$ classe + um a três meses e $6^{\text {a }}$ classe + seis meses.

A segunda fase vai de 1977 até 1989. Como resultado das experiências obtidas no período anterior, a Frelimo volta, no período subseqüente, a colocar a educação como uma das áreas prioritárias do desenvolvimento, daí a concentração de recursos do Estado na formação de professores. Importa destacar que este período encerra muitos eventos importantes do Partido Frelimo. O primeiro foi marcado pela realização do III Congresso, entre 3-7 de fevereiro de 1977 no qual a Frelimo se afirmou como um "Partido de Vanguarda Marxista Leninista" (DARCH, 1981, p. 111) e o IV Congresso, entre 26-30 de Abril de 1983. 
Para educação, o ano de 1983 marca a implementação do Sistema Nacional da Educação (SNE), criado pela lei 4/83, de 23 de Março, e revista pela lei 6/92, de 6 de Maio. Infelizmente a introdução do SNE coincide com um período em que o país atravessava uma crise sem precedentes.

(...) a situação económica não era a melhor em relação à que precedera o III Congresso. (...). A guerra e a seca haviam agravado a crise económica. A confiança para com o Partido era diferente. (...). O PGS [Plano Geral Social] decresceu para 6, 9\%, só em 1982, e em $35 \%$, de 1981 a 1986, decréscimo justificado pelos efeitos da seca, da guerra interna, das agressões militares e sabotagens econômicas da África do Sul, que afectaram negativamente a agricultura e outros sectores económicos e sociais, reflectindo-se, de imediato, na dinâmica das relações exteriores do país. (MAZULA, 1995, p. 171-172).

Essa crise condicionou o funcionamento do sistema educaional, obrigando o governo a redefinir suas estratégias, por exemplo, o fechamento de algumas escolas e criação de escolas completas devido à falta de professores. As escolas completas são aquelas que leccionam todas as classes definidas pelo SNE, isto é da $1^{\mathrm{a}}-7^{\mathrm{a}}$ classe. Com esta medida, surgem os modelos de $6^{\text {a }}$ classe +3 anos, $7^{\text {a }}$ classe +3 anos, por forma a tornarem flexível a formação dos professores para atender às necessidades do novo modelo de escolas completas.

A terceira e última fase, conhecida como momento de reforma do SNE e da reconstrução da rede escolar, parte de 1990, com a entrada em vigor da nova Constituição da República em 1990 até os nossos dias. De acordo com Minedh (2017, p. 47), "É um período de estabilidade social e de crescimento económico, caracterizado pela retomada do investimento na educação" (MINEDH, 2017, p. 47). Neste período, foram criados, por exemplo, o modelo $10^{\mathrm{a}}$ classe +2 e o modelo $10^{\mathrm{a}}+1+1$ e funcionaram nos chamados Institutos de Magistério Primário (IMAPs), oferecendo cursos 
para a formação de professores do Ensino Primário do $1^{\circ}$ e $2^{\circ}$ Graus (EP1 e EP2, respectivamente). Segundo Donaciano, o modelo $10^{\mathrm{a}}+2$, iniciou oficialmente em 1997, depois da experiência-piloto em 1996, na Munhuana, Cidade do Maputo. Em 1999, começou o modelo $10^{\text {a }}$ classe +1 ano de formação inicial presencial na instituição, mais um ano de estágio numa escola primária, designado por 10ª+1+1 (DONACIANO, 2006, p. 30).

$\mathrm{O}$ acontecimento mais importante deste período foi a introdução do novo currículo do ensino básico, em 2004, impondo nova dinâmica na formação de professores primários. Foi preciso formar professores dotados também de conhecimentos ncessários para leccionar no ensino bilíngüe. $\mathrm{O}$ ensino bilíngüe foi introduzido com o intuito de alfabetizar os alunos em língua materna.

A aprendizagem da língua materna adquire um lugar importante no atual currículo do ensino básico, entendida como uma das inovações de maior relevo, principalmente, a nível psico-pedagógico e cognitivo. Entendese que o ensino da L1 facilita a interação na sala de aula, visto que o aluno, por conhecer a língua, tem maior facilidade de comunicação (MINED, 2003, p. 130). Na verdade, fica fácil aprender a nossa língua materna, porque é por meio dela que construimos as bases da nossa humanização. Defendendo essa posição, Volochinov entende que a língua materna "é percebida como uma roupa habitual ou, melhor ainda, como aquela atmosfera costumeira na qual vivemos e respiramos. Nela não há mistérios; (...)” (VOLOCHINOV, 2017, p. 188). Nesse aspecto, o professor funcionaria como mediador cultural, colocando-se numa posicão privilegiada em relação ao outro com quem os alunos vão interagir.

A interacção ocupa um lugar chave na arquitectura linguística dos estudiosos do marxismo e filosofia da linguagem. Ela constitui-se como realidade fundamental da língua e se refere a qualquer comunicação discursiva (VOLOCHINOV, 2017, p. 219). A interacção resulta do confronto entre as posições axiológicas que constituem a própria natureza social da linguagem. 
A nova estrutura do ensino básico é composta por três ciclos de aprendizagem e o desenvolvimento do modelo bilingue adoptado tem em conta este aspecto. No primeiro ciclo ( $1^{\text {a }}$ e $2^{\text {a }}$ classes), as crianças são ensinadas em língua moçambicana como língua de instrução e o Português como disciplina. Neste ciclo, o Português visa ao desenvolvimento da oralidade, preparando a aprendizagem da leitura e escrita no ciclo subsequente. Já no segundo ciclo $\left(3^{\mathrm{a}}, 4^{\mathrm{a}}\right.$ e $5^{\mathrm{a}}$ classes) regista-se um fenómeno inverso. Assim na $3^{\text {a }}$ classe, o meio de instrução é ainda a L1, porém inicia o processo de ensino da leitura e da escrita em Português, através de um processo de transferência de habilidades adquiridas na L1; a partir da $4^{\text {a }}$ classe a língua portuguesa passa a ser língua de instrução, enquanto a L1 passa a ser auxiliar, nas disciplinas de Matemática, Ciências Naturais, Ciências Sociais. No fim do segundo ciclo, isto é, na $5^{\text {a }}$ classe, tanto os alunos do programa bilingue quanto os do programa monolingue são submetidos a um exame nacional. E, no terceiro ciclo, e último, prevê-se que a língua portuguesa seja o único meio de ensino-aprendizagem. E segundo essa previsão, a L1 será leccionada como disciplina e, eventualmente, como língua auxiliar. No final deste ciclo, fim do ensino básico, está previsto um exame final em língua portuguesa.

Essa nova configuração do ensino básico e no espírito de formação acelerada dos professores surge um modelo de $10^{\mathrm{a}}+1$ para formar professores que leccionam o ensino bilíngüe. É este o modelo que predomina muito nos dias de hoje. Para nós, esse modelo significa retrocesso, considerando que os graduados da décima classe têm muitos problemas lingüísticos. Neste aspecto, nossa sugestão aponta que mais do que a multiplicação de modelos, deveria apostar-se muito nas habilitações de ingresso nos cursos de formação de professores primários e na qualidade dos formadores. A $12^{\mathrm{a}}$ classe como habilitação mínima dos candidatos a cursos de formação de professores primários e o nível de Mestrado para os formadores e uma base sólida na área do ensino bilíngüe fundamentada pela 
perspectiva marxista e e filosofia da linguagem podem colocar-se como alternativa possível para a superação dos problemas actuais.

\section{Repensando o campo da formação de professores}

$\mathrm{Na}$ referência sistemática à formação de professores como conceito e prática (AGIBO, 2017) as discussões acadêmicas de integração dos conhecimentos disciplinares, didático-pedagógicos, metodológicos e experiências partilhadas na profissão com outros professionais, conhecimentos locais vindos da comunidade e dos alunos são facetas diversas dessa mesma preocupação.

Para tornar isso possível, há, a nosso ver, um caminho: a reconstrução das instituições de formação como espaços sociais e abertos. É preciso antes, reformular o conceito de forma+ação, enquanto derivado do verbo formar que em latim, significa dar forma diferente a um objeto. Assim, se pode aplicar na atividade de qualquer artesão, um escultor, etc. Esses transformam a forma original dos objetos, dando-lhes uma forma diferente da que tinha inicialmente. O que é certo é que o objeto e o homem não são a mesma coisa. Não se pode moldar o homem do mesmo jeito que se molda um objeto.

O objecto é "uma pura coisa morta, dotada de apenas aparência, só existe para o outro e pode ser totalmente revelada por ato unilateral do outro." (BAKHTIN, 2018, p. 395). Só tomando o homem como objeto, é que se pode admitir a hipótese de que a instituição de formação forma professores no sentido do verbo formar em latim. Mas, o homem, diferentemente do objecto manipulável ao bem do gosto do artesão, ele é “ um ser expressivo e falante" (BAKHTIN, 2018, p. 395). Isso significa que ele é membro ativo dentro de uma relação social com os outros seres seus semelhantes e de algum modo ele mesmo é responsável pela sua humanização e formação. Neste sentido, Nóvoa (2019) tem razão, ao afirmar que "o professor tem que se assumir como produtor da sua profissão" (NÓVOA, 2017, 1116). O autor 
entende que alguém “torna-se professor” (NÓVOA, 2017, 1116) como uma ação que recai sobre o próprio sujeito que a pratica.

Entendemos que a força deste para produzir a sua própria profissão está na capacidade de a instituição de formação abrir novas frentes de formação, mas que não se fecham no ensino das disciplinas de forma verticalizada, como diz o próprio Nóvoa (2017, p. 1116), referindo-se à falta de ligação entre a formação dos professores e a vida real que atravessa os sujeitos que aprendem. Com essas palavras, o autor leva-nos a pensar que não é possível formar professores sem uma abertura à sociedade, sem um conhecimento da diversidade das realidades culturais que hoje definem a educação.

$\mathrm{Na}$ verdade, nada substitui o conhecimento, mas o conhecimento de que um professor de uma língua necessita é diferente daquele que se exige a um lingüista. Ao professor não se exige um conhecimento menor ou simplificado. Mas "um conhecimento diferente, ancorado na compreensão da disciplina, da sua história, dos seus dilemas e, acima de tudo, das suas potencialidades para a formação de um ser humano" (NÓVOA, 2017, p. 1116).

Esse conhecimento é integrado (AGIBO, 2017), pois envolve muitos saberes profissionais docentes (SHULMAN, 2005; TAMIR, 2005; TARDIF, 2002; LIBÂNEO, 2015), referindo-se a conhecimentos didáticos, gerais e especificos, conhecimentos curriculares, conhecimentos dos alunos, conhecimentos dos objetivos e finalidades educativas.

É dessa base que defendemos que a formação de professores deveria começar a preocupar-se, de fato, com a formação humana.

\section{Concepções da linguagem e estudos bakhtinianos}

O nome de Bakhtin vem sendo uma referência incontornável na área da linguagem como instrumento da formação humana. Em seus trabalhos, os estudiosos do marxismo e filosofia da linguagem criticam a maneira como 
se construiu e se enraizou a visão tradicional sobre o ensino da linguagem. Segundo Stella (2018, p. 177):

A Gramática, em consequência de uma tradição de estudos grecolatinos, seccionava a palavra e organizava suas partes em paradigmas de flexão declinação. A Filologia, por sua vez, descrevia a evolução histórico-fonética da palavra com a observação de documentos. A Linguística passava, naquele momento, por duas fases de observação da palavra: numa delas, organizava as línguas em suas famílias e respectivas ramificações de acordo com as suas origens, estudando as palavras em documentos e, na outra, percebendo o funcionamento sistemático da linguagem, descrevia as relações estruturais em vários níveis a partir da palavra. A semântica constituía um desses níveis de descrição estrutural da linguística e os estudos sobre o sentido das palavras formavam dois ramos distintos dessa disciplina: a semasiologia, da perspectiva sincrônica e estrutural, distinguia os traços de significação constituintes do significado da palavra dentro de um sistema; e a onomasiologia, da perspectiva diacrônica e conceitual, pretendia a uma origem comum de sentido das palavras nas várias línguas independentemente das variantes fônicas de expressão.

Desde as primeiras décadas do século $\mathrm{XX}$, nos trabalhos de Volochinov (2017) a linguagem, em geral, é tratada de uma forma diferente, levando-se em conta a sua história, sua historicidade, ou seja, especialmente a linguagem em uso. $\mathrm{Na}$ teoria elaborada pelos estudiosos do chamado círculo bakhtiniano, o conceito de história é um dos conceitos dominantes, os quais fazem parte deste debate.

O ser humano é antes um ser biológico, contudo para ser um sujeito histórico deve ter um segundo nascimento social que lhe permite construir a sua existência, em decorrência das relações com a produção cultural 
disponível. A história é um ir e vir, ou seja, um fenómeno em movimento. Não está estagnada, nem pronta, nem acabada. Assim, ela como a linguagem surgem nas relações sociais, facto que leva os estudiosos do marxismo e filosofia da linguagem a valorizarem o outro na comunicação e na constituição dos sujeitos.

É preciso, antes, recordar que a linguagem nasce da necessidade de comunicação entre os homens. Com o passar do tempo, ela evoluiu, desempenhando funções diferentes na vida das pessoas. Segundo Volochínov (2013, p. 155):

Inicialmente [a linguagem] se compõe de gestos, da mímica, e depois do material sonoro. Servindo a estas necessidades de comunicação dos homens, a linguagem serve ao mesmo tempo como instrumento particular de um processo econômico, serve de conjunto mágico. Sendo produto da vida social, refletindo-a não só no campo da vida semântico mas também nas formas gramaticais, a linguagem tem ao mesmo tempo uma enorme influência sobre o desenvolvimento da vida económica e sócio-política.

Com a função social, a linguagem pressupõe, para realizar-se, a existência de dois interlocutores: um Eu e um outro. Parece, então, que a noção do outro está em conformidade com a perspectiva de Jakubinskij, que trata da linguagem como atividade linguageira isto é, como língua em acção. É por isso um facto sociológico, já que depende da vida colectiva em interacção com outro (JAKUBINSKIJ, 2015, p. 50). Para Bakhtin, é na relação com a alteridade que os indivíduos se constituem. Bakhtin (1997, p. 47) afirma que:

Quando me identifico com o outro, vivencio sua dor precisamente na categoria do outro, e a reação que ela suscita em mim não é o grito de dor, e sim a palavra de reconforto e o ato de assistência. Relacionar o que se viveu ao outro é a condição necessária de uma 
identificação e de um conhecimento produtivo, tanto ético quanto estético.

Nessa perspectiva, o outro adquire um valor excepcional para a construção da identidade do sujeito, cujos pensamentos, opiniões, visões do mundo, ideologias, etc. se constituem e se elaboram a partir de relações dialógicas e valorativas com outros sujeitos.

Falando das ideologias, este é também uns dos conceitos que interessam à nossa reflexão.Volóchinov (2017) entende que a ideologia não pode derivar da consciência individual, como pretendem o idealismo e o positivismo psicologista, mas da consciência colectiva e se constrói em todas as esferas das interacções. A ideologia é dialecticamente ligada ao signo. No dizer de Volóchnov (2017, p. 91):

Qualquer produto ideológico é não apenas uma parte da realidade natural e social - seja ele um corpo físico, um instrumento de produção ou um produto de consumo - mas também ao contrário desses fenómenos, reflecte e refrata outra realidade que se encontra fora dos seus limites. Tudo o que é ideológico possui uma significação: ele representa e substitui algo encontrado fora dele, ou seja ele é um signo. Onde não há signo também não há ideologia.

Reforçando esse pensamento, urge esclarecer que a ideologia carrega, em sua constituição, num vértice uma oficialidade que o faz pertencer a um determinado sistema ideológico, e, noutro, um conjunto de valores e ideias que se constitui pela e na interacção verbal travada entre e por sujeitos pertencentes a diferentes grupos, desde que estes estejam socialmente constituídos e organizados na história concreta.

Assim, Volochínov (2017, p. 95), ao encarar a palavra como signo ideológico, parte do seguinte pressuposto: a palavra é bi-facial porque possui duas faces: ela procede de alguém e se dirige a alguém, assim 
sucessivamente, e, mais, ela tem poder que impõe um determinado comportamento e uma certa atitude mais apropriada à colectividade linguística e social em que é produzida, viabilizando estabilidades nas práticas sociais de linguagem.

Mas esse comportamento não é pronto nem acabado, pois se assim fosse, os indivíduos não teriam capacidades de questionar, modificar, alterar certos comportamentos tidos estáveis. Todo o enunciado é susceptível de ter respostas. Isto significa que o ouvinte, ao compreendê-lo, ocupa simultaneamente em relação a ele uma atitude responsiva: concorda ou discorda dele (total ou parcialmente), completa-o, aplica-o, prepara-se para usá-lo, etc. Essa atitude responsiva do ouvinte se forma ao longo de todo o processo de audição e compreensão (BAKHTIN, 2017).

Contudo, é necessário não confundirmos o processo de compreensão com o processo de reconhecimento.

Eles são profundamente diferentes. Apenas um signo pode ser compreendido, já o sinal é reconhecido. O sinal é um objeto internamente imóvel e unitário que, na verdade, não substitui, reflete ou refrata nada, mas é simplesmente um meio técnico através do qual se aponta para algum objeto (definido e imóvel!) ou para alguma coisa (também e imóvel!). O sinal jamais deve ser relacionado à área do ideológico; ele é parte do universo de objetos técnicos e dos instrumentos de produção no sentido amplo dessa palavra (VOLOCHINOV, 2017, 178).

Volochínov, ao submeter o subjectivismo idealista e o objectivismo abstracto à prova, tinha em mente que a língua não pode ser explicada a partir da vida psíquica dos sujeitos da fala, nem ela pode ser dada aos sujeitos como uma entidade acabada e pronta a ser usada. Disso decorre que o papel do sujeito-aluno se torna fundamental, já que se constitui pelo fenómeno social de interacção verbal, resultante do diálogo, seja este de carácter oral ou escrito. E por seu turno, o sentido do diálogo dá-se pela 
compreensão de dois indivíduos socialmente organizados. Para Volochínov (2017, p. 205):

A palavra é orientada para o interlocutor, ou seja, é orientada para quem é esse interlocutor: se ele é integrante ou não do mesmo grupo social, se ele se encontra em uma posição superior ou inferior em relação ao interlocutor (em termos hierárquicos), se ele tem ou não laços sociais mais estreitos com o falante (pai, irmão, marido etc.).

Compreendemos também que a orientação da palavra para o interlocutor, cuja materialidade fundamental decorre da interacção verbal, é extremamente importante. Segundo o autor,

Em sua essência, a palavra é um ato bilateral. Ela é determinada tanto por aquele de quem ela procede quanto por aquele para quem se dirige. Enquanto palavra, ela é justamente o produto das inter-relações do falante com o ouvinte. Toda palavra serve de expressão ao "um" em relação ao "outro". Na palavra, eu dou forma a mim mesmo do ponto de vista do outro e, por fim, da perspectiva da minha coletividade. A palavra é uma ponte que liga o eu ao outro. Ela apoia uma das extremidades em mim e a outra no interlocutor. A palavra é o território comum entre o falante e o interlocutor (VOLÓCHINOV, 2017, p. 205).

Uma coisa é certa, tudo o que ronda a concepção sociológica do Círculo de Bakhtin e, aqui, deve ser sublinhado e explicado, parece uma recusa a qualquer tipo de trabalho formal com a linguagem. Isso não é verdade, porém o que os autores negam é o desmembramento do homem dos seus actos linguareiros, isto é, estudar formal e tecnicamente a língua fora da enunciação. Volóchinov, (2017, p. 242) afirma que: 
para uma maior compreensão da língua e de sua constituição, os problemas de sintaxe possuem enorme importância. Pois de todas as formas da língua, as sintáticas são as que mais se aproximam das formas concretas do enunciado, isto é, daqueles dos discursos verbais concretos. Todos os desdobramentos sintáticos do discurso desintegram o corpo vivo do enunciado, e por isso são os que geram mais dificuldades ao serem relacionados ao sistema abstrato da língua. As formas sintáticas são mais concretas do que as morfológicas e as fonéticas e, estão ligadas de modo mais estreito às condições reais da fala. Por isso, na nossa compreensão dos fenómenos vivos da língua, justamente as formas sintáticas devem ter primazia sobre as morfológicas e as fonéticas. No entanto, do que foi dito, também se torna claro que o estudo produtivo das formas sintáticas só é possível no terreno de uma teoria bem elaborada do enunciado. Enquanto o enunciado como um todo permanecer terra incógnita para o linguista, não se pode falar de uma compreensão real, concreta e não escolástica das formas sintáticas.

Por isso, a reflexão linguística volochinoviana é uma abordagem ampla e viva da língua, incompatível com a reflexão feita pela gramática tradicional, que organiza o estudo da língua, da frase e da palavra fora da enunciação.

\section{Por um novo caminho}

Antes de deixarmos ficar quaisquer considerações acerca do estudo feito, gostaríamos, em jeito de chave de leitura, esclarecer que a leitura deste texto é simeplesmente um ponto de partida para debates acerca do tema. Ao leitor deste texto cabe construir para cada segmento ou linha do texto uma narrativa que lhe permite ressigificar o sentido que nós já lhe atribuímos. Para nós, como autores, este texto é um exercício de expor mais 
as nossas limitações do que um pensamento pronto, por isso colocamo-nos à espera de uma crítica gentil, mas que nos permite repensar uma vez mais no tema.

Indo directo ao assunto, importa-nos destacar que no período em análise foram introduzidos muitos modelos de formação de professores, alguns dos quais foram substituídos antes da avaliação do seu impacto. Não nos foi possível registar todos os modelos, mas também temos em mente que, por alguma razão, podemos ter conferido uma data indevida a certos modelos de formação devido à falta de consenso das fontes consultadas. É de sublinhar também que excluímos deliberdamente os modelos de formação de professores desenvolvidos nas instituições de ensino superior como a Universidade Eduardo Mondlane, Universidade Pedagógica e Universidade Católica de Moçambique, pois nosso foco são os modelos de formação de professores primários.

Analisando de perto os modelos de formação introduzidos ao longo do tempo compreendemos que a organização curricular, ou seja as componentes de formação, os conteúdos disciplinares se alteraram quanto mudou a organização curricular da escola. Por exemplo, com a introdução do ensino bilíngüe no ensino primário, assistimos à ênfase, nos cursos de formação, para a componente de ensino bilíngüe. Surge no atual modelo de $10^{\mathrm{a}}+1$, a disciplina de Línguas Bantu, incluindo a Metodologia de Educação bilíngüe (cf. MINEDH, 2017, p. 59), ainda que em termos de distribuição da carga horária nos planos curriculares, a ênfase seja dada à língua portuguesa. $\mathrm{O}$ que nos leva a imaginar o papel organizador da língua estrangeira no processo de todas as culturas históricas. Segundo Bakhtin (2002, p. 188),

a palavra alheia estrangeira trazia luz, cultura, religião e organização política (...). Esse papel organizador sempre vinha acompanhado pela força e pela organização alheia ou era encontrado por um jovem povo conquistador no terreno de uma cultura antiga e poderosa ocupada por ele, como se ele 
escravizasse a consciência ideológica do povo conquistador a partir de túmulos. Como resultado, a palavra alheia, nas profundezas da consciência histórica dos povos, fundiu-se com a idéia de poder, de força, de santidade e de verdade, fazendo com que a noção de palavra se orientasse na maioria das vezes justamente para a palavra alheia.

Em contrapartida, a realidade efectiva da linguagem não é o poder, a força, a verdade, a organização política, a alienação da consciência ideológica (VOLOCHINOV, 2017, p. 218), mas o acontecimento social da linguagem que ocorre por meio de várias linguagens.

\section{Conclusão}

Em Moçambique, um país multilíngüe, o plurilinguismo se opõe ao monolinguismo oficial da língua portuguesa que pretende ser a única linguagem a determinar os modos de operar em todas as esferas sociais, educação, saúde, admnistração, entre outas. No plurilinguismo, todos os sujeitos e suas linguagens são, igualmente, relevantes. Não há línguas e cultura inferiores nem superiores. Desse modo, o conceito de plurilinguismo adquire uma importância fundamental, porque releciona-se com a cultura, o que nos leva a pensar que valorizar uma língua qualquer que seja é reconhecer a cultura e os falantes dessa língua.

Em outras palavras, é aceitar outras maneiras de pensar, de encarar a realidade e de agir. Em Moçambique faz algum tempo que as vinte e quatro línguas reinvindicam o seu lugar de reconhecimento, o que somente a partir de 2004 começa a tornar-se explícito e, pela primeira vez, faz parte do currículo de formação de profesores primários.

Outro aspecto importante que pode ser observado nos planos curriculares de formação de professores é o da prevalência excessiva do método fônico, tanto no programa de Português quanto no Guião de 
Educação Bilíngüe, esvaziando a apropriação da linguagem, ao insistir no estudo isolado da letra e da sílaba. Dessa prática discordamos se tivermos em conta os estudos de Volochinov. Segundo o autor: "Se isolarmos o som como um fenômeno puramente acústico, não teremos a língua como objeto específico." (VOLOCHINOV, 2017, p. 144). A natureza da linguagem é social, pelo que deve ser estudada no meio onde acontece, isto é nas relações sociais dos sujeitos.

Importa destacar que até aqui as mudanças operadas no processo de formação de professores em Moçambique são relevantes, sobretudo porque foram feitas procurando se ajustar à dinâmica econômica, social e política. Como vimos, quando a estrutura da escola passou a integrar mais alunos, o fenômeno da formação de professores também sofreu alterações. O mesmo podemos ver, quando o Estado começou a fragilizar-se devido à guerra e à baixa economia; também quando o país adopta uma economia concorrencial e uma democracia multipartidária, a formação de professores foi afetada. Isso é fundamental. Mas, a nosso ver, a formação dos professores deve ampliar o compromisso com os sujeitos.

\section{Referências}

AGIBO, J. B. Formação de professores para o ensino básico em moçambique: análise do modelo de formação $10^{\mathrm{a}}+1$ ano. caso dos institutos de formação de professores da província de nampula (2007-2016). 2017. 106f. Dissertação (Mestrado em educação) - Faculdade de Filosofia e Ciências. Universidade Estadual Paulista - Unesp. Marília, 2017.

BAKHTIN, M. Estética da criação verbal. Fontes. São Paulo: Martins Fontes, 1997. Os géneros do Discurso. Sao Paulo: Editora 34, 2016.

Questões de Literatura e de Estética: A teoria do romance. São Paulo: Hucitec, 2002.

DARCH, C. As publicações da Frelimo: um estudo preliminar. Estudos Moçambicanos. Maputo, publicações da Frelimo, 1981, p. 102-120.

DONANCIANO, B.. A formação de professores primários em Moçambique desenvolvimento da competência docente dos formandos durante o estágio, no 
modelo 10a $+1+1$. 2006. 185f. Dissertação (Mestrado em Educação/Currículo). Pontifícia Universidade Católica de São Paulo em Convénio com a Universidade Pedagógica de Maputo, 2006.

FARACO, C. A. GILBERTO de. Por uma teoria linguística que fundamente o ensino de língua materna (ou de como apenas um pouquinho de gramática nem sempre é bom). Educar em revista, 15, 1999, pp. 1-9. Disponível em $<$ http://dx.doi.org/10.1590/0104-4060.200. acesso em mar. 2019>.

JAKUBINSKIJ, L. Sobre a fala dialogical. Trad. Dóris de Arruda C. da Cunha e Suzana Leite Cortez. Parábola. São Paulo, 2015.

Lei 6/92 de 6 de Maio, do SNE adequada as disposições contidas na Lei $\mathrm{n}^{0}$ 4/83. Boletim da República II SÉRIE-NÚMERO 19.

Lei $n^{\circ} 4 / 83$ de 23 de Março, que aprova a Lei do Sistema Nacional de Educação e define os princípios fundamentais na sua aplicação. Publicada no Boletim da República, II SÉRIE- Número 12.

LIBÂNEO, José Carlos. Formação de Professores e Didática para Desenvolvimento Humano. Educação \& Realidade. Porto Alegre, v. 40, n. 2, p. 629-650, 2015. Disponível em <https://seer.ufrgs.br/educacaoerealidade/article/view/46132>. Acessado em 29/jul/2019.

MAZULA, B. Educação, cultura e a ideologia em Moçambique. Maputo: Edições Afrontamento e Fundo Bibliográfico da Língua Portuguesa, 1995.

MINEDH. Relatório do Estudo Holístico da Situação do Professor em Moçambique, 2015. Maputo, MINEDH, 2017.

INDE/MINED, Plano Curricular do Ensino Básico (PCEB) - Objectivos, Política, Estrutura, Planos de Estudo, e Estratégias de Implementação. Maputo: INDE/MINED, 2003.

MOÇAMIQUE. Constituição da República Popular de Moçambique. Maputo, 23 de Dezembro de 1977: INLD. 1997.

MINED. Estratégia para formação de professores, 2004 - 2015: proposta política. Maputo: INDE, 2004.

NGUNGA, A.; BAVO, N. N. O. G. Práticas linguísticas em Moçambique: Avaliação da vitalidade linguística em seis distritos. Maputo: Autores, 2012.

NGUNGA, A.; FAQUIR, O. G. Padronização da Ortografia de Línguas Moçambicanas: Relatório do III Seminário. Maputo: Autores, 2012.

NÓVOA, A. Firmar a posição como professor, afirmar a profissão docente. Cadernos de Pesquisa, 166, pp. 1106-1133, 2017. Disponível em 
http://www.scielo.br/pdf/cp/v47n166/1980-5314-cp-47-166-1106.pdf . Acesso em: 12 de Mar. 2019.

SHULMAN, L. Conocimiento y Enseñanza: fundamentos de la nueva reforma. Profesorado. Revista de Currículum y Formación del Profesorado, v. 9, n. 2, p. 1-30, 2005. Disponível em: <https://www.ugr.es/ recfpro/rev92ART1.pdf>. Acesso em: 24 abr. 2019.

STELLA, P. R. Palavra. In: BRAIT. (Org.). Bakhtin: Conceito-Chave. São Paulo: editora contexto, 2018. pp. $177-190$.

TAMIR, P. Conocimiento Profesional Y Personal De Los Profesores Y De Los Formadores De Profesores. Revista de currículum y formación del profesorado, v. 9, n. 2, p. 1-10 2005. Disponível em: <https://www.ugr.es/ recfpro/rev92ART1.pdf>. Acesso em: 24 abr. 2019.

TARDIF, M. Saberes Docentes e Formação Profissional. Petrópolis: Vozes, 2000.

VOLOCHÍNOV. V. N. A Construção da Enunciação e Outros Ensaios. São Paulo: Pedro \& João Editores, 2013.

Marxismo e filosofia da linguagem. São Paulo: Hucitec, 2017.

Recebido em Abril de 2019.

Aprovado em setembro de 2019. 